\title{
Sustainable effluent irrigation over the past decade - The role of MEDLI modelling for wastewater discharge
}

\author{
$\underline{\text { A.M. Vieritz }}^{\text {a }}$, I.R. Ramsay ${ }^{\text {a }}$, L.F.J. Haworth, S. Tennakoon ${ }^{\text {a }}$ and E.A. Gardner ${ }^{\text {a }}$ \\ ${ }^{a}$ Department of Environment and Resource Management, Queensland \\ Email: alison.vieritz@derm.qld.gov.au
}

\begin{abstract}
Effluent irrigation has been an increasingly important option for reusing and disposing of effluent produced by intensive rural industries, sewage treatment plants and domestic on-site systems over the past few decades. Over this time, regulatory controls on the environment have become more stringent, as effluent irrigation schemes in Queensland continue to be located in tropical and sub-tropical areas, often with conditions adverse to their successful establishment such as high rainfall and poor soils. MEDLI (Model for Effluent Disposal using Land Irrigation) has been used by designers and regulators over the past 15 years to assess the environmental impact of effluent irrigation schemes.

In this paper, the usefulness of the MEDLI model over the past decade in effluent irrigation assessments is reviewed, including what has performed well and what could be improved. Since its development by the Cooperative Research Centre for Waste Management and Pollution Control Ltd, Commonwealth Scientific and Industrial Research Organisation (CSIRO), and the Queensland Department of Primary Industries (now the Department of Environment and Resource Management), MEDLI has enjoyed reasonable success in its uptake and use by consultants, regulators, industry, and universities around Australia and overseas. The majority of Queensland effluent irrigation designs now use MEDLI, not the least reason being that it was recommended as the design tool in the Queensland effluent reuse guidelines for both sewage treatment plants and animal industry enterprises. It remains in use despite suffering the incompatibility problems associated with all legacy software developed pre-Windows 2000. Its success has been attributed to a number of factors including: the absence of a similar model that performs the same task; the difficulty and cost of developing modelling software for such a small niche market; clear benefits to a target user audience, the scientific integrity of the model (in terms of algorithms and peer review process), low purchase cost; and ongoing support provided by model developers themselves. These factors and other lessons from our interaction with MEDLI users will be discussed in the paper.
\end{abstract}

The critical issue for effluent irrigation scheme designers is not just one of predicting water, nutrient and salt outcomes of a particular design, but also is one of interpreting results in terms of performance criteria. How do we interpret the results such as frequency of pond overtopping, percentage of the effluent that is reused, and nitrate concentration in the soil solution leachate in terms of sustainability? What number is acceptable and what number is unacceptable? It is our view that environmental protection policy and guidelines are needed to help address these questions and we introduce possible performance criteria to help determine if a model result is acceptable or unacceptable.

We discuss the application of MEDLI to assess irrigation proposals, with a particular focus on its use to assist enlightened environmental regulation in Queensland. A risk-based policy framework is proposed to guide the assessment of effluent irrigation schemes in the future. This is designed to help address the key issue of identifying non-sustainable practice, along with planned improvements in the modeling software/application framework to support this approach.

Keywords: MEDLI model, effluent irrigation scheme design, sustainability, performance criteria, risk-based assessment. 


\section{INTRODUCTION}

Since the mid-1990s, effluent irrigation has come under increasingly stringent regulatory controls. In addition, effluent irrigation schemes in Queensland continue to be located in tropical and sub-tropical areas, often with conditions adverse to their successful establishment such as high rainfall and poor soils. Disposal of agri-industry and sewage effluent by land irrigation offers the advantage of returning water and nutrients to the land supporting crop growth rather than direct release to surface waters where these nutrients can have detrimental environmental effects. Nonetheless, land irrigation of effluent needs to be undertaken in a sustainable manner such that environmental impacts are kept within acceptable levels, so that the environmental resource is available for future generations.

Predicting the long-term environmental impacts of a proposed effluent irrigation scheme is not a simple task due to the complex nature of the interactions that take place within the effluent irrigation system defined by effluent generation, pond storage and land irrigation. For example, waste streams from piggeries will vary greatly depending on whether recycling of effluent is adopted for cleaning. Of the wastewater applied to the irrigation area, only a small portion will result in runoff, or be lost to the groundwater as deep drainage, while the remainder will mainly be lost via evapotranspiration. A portion of the nutrients will be taken up by plants leaving the remainder to be lost to runoff, deep drainage or stored in the soil profile. Some nutrients will be adsorbed on to soil particles whilst others will be transformed to gaseous forms or freely leached with draining water (i.e. $\mathrm{NO}_{3}$ ). These complexities led to the need for a biophysical model of the effluent irrigation system to help provide insights into how such schemes can be designed and operated to minimise the risk of adverse environmental impacts. MEDLI (Model for Effluent Disposal using Land Irrigation) has been widely used by effluent irrigation scheme designers and regulators over the last 15 years for this purpose.

In this paper we discuss the application of MEDLI to assess irrigation proposals with a particular focus on its use to assist enlightened environmental regulation in Queensland. We introduce possible performance criteria to help determine if a model result is acceptable or unacceptable. A risk-based policy framework to guide the assessment of effluent irrigation schemes in the future is also presented, along with some improvements in the modelling software/ application framework.

\section{A RETROSPECTIVE ON THE MEDLI MODEL}

MEDLI is a biophysical daily timestep simulation model that incorporates the scientific understanding of how water and nutrients are partitioned through space and time in an effluent generation, storage, treatment and reuse system. The system includes the waste generator, a pond treatment system, an irrigation area where plants can be grown, and an underlying groundwater aquifer. Descriptions of this model can be found in a number of publications (Davis and Gardner 1996; Gardner et al. 1996; Vieritz et al. 1998). It was developed by the Cooperative Research Centre for Waste Management and Pollution Control Ltd, Commonwealth Scientific and Industrial Research Organisation (CSIRO) and the then Queensland Department of Primary Industries (QDPI) and released in 1996 to assist designers of effluent disposal systems and government regulators to better design sustainable land disposal systems; allow them to ask 'what if' questions, and to predict the effectiveness of existing or proposed practices.

Over the two years after the release of MEDLI, there were 32 sales to 27 clients and about 10 regular users emerged. Schofield (2005) in an independent review of the initial success of MEDLI, concluded that the prime reason for the lower than expected market penetration was the "effort [needed] to become competent in the use of MEDLI. Other contributing factors were the absence of advertising, an initially high price, set by the model distributer, existing competition and downturn in the intensive livestock industries".

With the release of Service Packs for the Microsoft Windows 2000 Operating System, MEDLI suffered incompatibility problems associated with legacy software developed pre-Windows 2000. Altering MEDLI to run under modern operating systems requires a substantial rewrite of the MEDLI program which had never been budgeted for. Funding for the MEDLI ceased in 1998 with the release of the Version 1.3. As evidence of the industry worth of MEDLI, users then resorted to running the software on computers with pre-Windows 2000, Windows 2000 with service packs uninstalled, or more often, installed emulation software running WINDOWS 2000 within a later version of the operating system.

Nevertheless, Schofield (2005) estimated that MEDLI was used in 90\% of Queensland effluent irrigation designs, not the least reason being that it was recommended as the design tool in the Queensland effluent reuse guidelines for both sewage treatment plants and animal industry enterprises (EPA 2005). However, in other states, MEDLI was used in perhaps 5\% of investigations. Schofield (2005) suggests that this was due to 
the existence of locally developed models (usually spreadsheets) which were better known and sometimes better suited to obtain regulatory permission based on the local guidelines. The effluent reuse guidelines for NSW, Victoria and Tasmania all describe locally developed water balance programs that can be used to design the irrigation scheme. However they are usually simplistic in terms of dynamic plant growth, nutrient and salt balances.

To date, MEDLI continues to be used for the design and assessment of effluent irrigation schemes, with approximately 150 copies sold around Australia and overseas. The software is predominantly used by consultants (70\%), State and Local Government regulatory agencies $(20 \%)$, and by universities and industry $(10 \%)$. Although these numbers are still low, the market for such specialist software was never expected to be large.

Overall, MEDLI is regarded as a successful model in terms of making a significant positive impact on the design and appraisal of effluent irrigation schemes in Queensland (Schofield 2005). Factors which have impacted on the uptake of MEDLI are presented in Table 1. The fact that it is still viable 15 years after its release, despite some significant hurdles including a high initial effort to gain competency in its use, lack of software upgrades, lack of advertising, and the relative small market, is believed to be testimony to its holistic nature, its scientific rigor, market need and free support by the model developers.

Following the merge of Department of Natural Resources and Water (a successor of QDPI) with Environmental Protection Agency to form the Department of Environment and Resource Management (DERM) in 2009, the MEDLI project has been revitalised. This has been due to the perseverance of regulators and designers in using MEDLI rather than any policy change. The formation of DERM has provided the financial and staff resources for model developers and regulators to work together in the on-going redevelopment of MEDLI.

\section{EFFLUENT IRRIGATION SCHEME ASSESSMENT USING MEDLI}

Irrigation schemes for the disposal of wastewater usually require some type of environmental assessment before approvals can be granted. As mentioned in Section 2, the MEDLI model has been the most commonly used tool to assist decision makers in Queensland over the last decade.

Table 1. Key factors that have influenced the uptake of the MEDLI model over the past 15 years. (Negative factors are shaded)

\begin{tabular}{|c|c|}
\hline Key Factors & MEDLI Uptake Review \\
\hline Authorship & $\begin{array}{l}\text { MEDLI was developed in close collaboration with government; by QDPI, CSIRO and Cooperative Research } \\
\text { Centre for Waste management and Pollution Control; all respected research organisations. }\end{array}$ \\
\hline Model algorithms & Algorithms which had been extensively tested and applied in other models were adopted in MEDLI (Hook 1997). \\
\hline Model scope & $\begin{array}{l}\text { MEDLI models the effluent stream of a whole enterprise from its production through to the disposal area including any } \\
\text { pond treatment system. It can be used to assess the effects of effluent recycling from ponds for cleaning in piggeries to } \\
\text { predict waste stream volume/composition (Davis and Gardner 1996). }\end{array}$ \\
\hline Peer-review & The software was documented, peer reviewed and tested against experimental data (Hook 1997, Vieritz et al. 1998) \\
\hline Product champion & MEDLI was well championed following its release via conference presentations and publications. \\
\hline Timing of release & $\begin{array}{l}\text { MEDLI's release coincided with an identified need for a decision support system on effluent disposal to assist both } \\
\text { designers and appraisers (Davis and Gardner 1996). }\end{array}$ \\
\hline $\begin{array}{l}\text { Users Outcomes/ } \\
\text { Benefits }\end{array}$ & $\begin{array}{l}\text { Its use by both regulators and scheme designers allowed the debate to shift from the method of prediction to the } \\
\text { inputs used and acceptability of outputs. Previously, many different tools were used (e.g. spreadsheet models build } \\
\text { in-house by designers and regulators). Documentation was usually poor \& testing was non-existent. }\end{array}$ \\
\hline Cost /price & $\begin{array}{l}\text { The software purchase price was initially set at a value commensurate with other models of its type/complexity at the } \\
\text { time. This was quickly dropped to } \$ 1000 \text { in the late } 1990 \mathrm{~s} \text {. This price did not attempt to provide recovery of } \\
\text { development or ongoing maintenance/support costs. }\end{array}$ \\
\hline User Support & $\begin{array}{l}\text { Support was supplied by developers and many of the queries then led on to model improvements. Support was } \\
\text { limited to phone and email. Some limited training and a set of tutorial notes were available. }\end{array}$ \\
\hline Size of market & $\begin{array}{l}\text { MEDLI is suited to specialist users who design and regulate effluent irrigation schemes. This is a relatively small niche } \\
\text { market. The intensive livestock industry was one main "target" audience and the down-turn of this industry in the } \\
\text { last decade affected the extent of use (Schofield 2005). }\end{array}$ \\
\hline Advertising & $\begin{array}{l}\text { No targeted advertising was adopted (Schofield 2005). Resources were not available to service a runaway marketing } \\
\text { success. }\end{array}$ \\
\hline Ease of use & $\begin{array}{l}\text { MEDLI required a steeper learning curve than many of the existing tools of the time, and requires frequent use to } \\
\text { maintain competency (Schofield 2005). }\end{array}$ \\
\hline $\begin{array}{l}\text { Software } \\
\text { maintenance }\end{array}$ & $\begin{array}{l}\text { Maintenance for the MEDLI software since } 1998 \text { was limited to reporting and providing work-arounds for faults } \\
\text { rather than fixing them through version updates. }\end{array}$ \\
\hline
\end{tabular}


Generally, MEDLI modelling is performed by effluent irrigation scheme designers who provide details of the proposed scheme to DERM to seek approval. The Department reviews the submission to check model inputs, and model predictions. In doubtful cases, DERM officers will re-run MEDLI using the supplied model inputs. If an application is approved, the conditions of approval are generally based on the model inputs. For example, the maximum flow rate and minimum area for irrigation are usually specified in the conditions based on the scenarios assessed. In general, a "good" number or result involves two levels of consideration. The first relates to the uncertainty of the model result (considering inputs, parameters and model integrity). The second relates to whether the result is acceptable in terms of both on-site and off-site impacts (considering model output values and other site factors). The process of assessing model inputs and predictions is discussed in more detail below. This is currently based largely on expert opinion and rules of thumb as the process and performance criteria for land disposal of effluent in Queensland have not been documented, unlike in other states of Australia (e.g. DEC 2004). Section 4 discusses a process and further criteria that could be used in the future for this purpose.

\subsection{Model Input Review}

MEDLI requires a large number of inputs and model parameters to simulate irrigation scheme performance in terms of crop growth, water balances and fate of nutrients. As for any deterministic model, appropriate inputs and model parameters are vital to achieve reliable model outputs. Therefore, the model inputs and parameters used are checked and verified by DERM for each irrigation assessment application. Some examples of important input parameters for MEDLI that usually require checking are given in Table 2.

\subsection{Model Output Review}

Unsustainable effluent irrigation can result in: degradation of the irrigation land from salinity, sodicity etc.; nuisance to neighbours from odours, overspray or runoff; impacts on water courses from excessive surface runoff containing nutrients or other pollutants; and impact on groundwater from leaching of pollutants such as salt or nutrients. MEDLI predictions can help assess risks associated with a number of these issues. However, the interpretation of predictions, particularly for impacts on the immediate environment, is not straight forward (also see Section 3.3). Table 3 lists some of the key MEDLI outputs which are typically reviewed, along with some triggers that are used to identify potential problems. These choices are largely based on expert opinion and experience.

\subsection{Other considerations}

Some information not considered by MEDLI is also important in the decision making process, particularly in terms of the potential impacts off-site. This includes information on topography of the irrigation area, distance to sensitive receptors (including water courses, water supply bore etc.), buffer zone and groundwater depth. This information, in combination with the MEDLI outputs, can be used to assess whether there are environmental issues of concern. Based on this assessment and that of other issues described in Section 3.2, the proposed scheme will be usually approved, or require modifications to its design and operation.

Table 2. Examples of input data checks carried out by Department of Environment and Resource Management for appraisal of an effluent irrigation scheme proposal.

\begin{tabular}{|l|l|}
\hline Attribute & \multicolumn{1}{|c|}{ Description of Check } \\
\hline $\begin{array}{l}\text { Historic climate } \\
\text { data }\end{array}$ & $\begin{array}{l}\text { Daily rainfall, pan evaporation, minimum temperature, maximum temperature and solar radiation data. Check } \\
\text { the site location and the geographical coordinates of historical climatic data (e.g. are site specific) and compare } \\
\text { data with the median/ mean values from Bureau of Meteorology data. }\end{array}$ \\
\hline Enterprise type & $\begin{array}{l}\text { Piggery, dairy, sewage treatment plant (municipal) and other (generic) are enterprise options within MEDLI. } \\
\text { Check the appropriateness of choice by the applicant. }\end{array}$ \\
\hline Effluent quality & Check that the relevant water quality characteristics of effluent have been provided. \\
\hline Pond size & $\begin{array}{l}\text { Check that the wet-weather storage pond volume is not less that that required for 20-30 days inflow (or more, } \\
\text { depending on length and severity of wet season). }\end{array}$ \\
\hline Land area & $\begin{array}{l}\text { Check that the land area is not less that the area calculated from Effluent Inflow (ML/yr) divided by the } \\
\text { Irrigation demand (ML/ha/yr) for the locality and plant grown. Irrigation demand can be approximated as } \\
\text { annual average evaporation (ML/ha) x crop coefficient - annual average effective rainfall (ML/ha). }\end{array}$ \\
\hline $\begin{array}{l}\text { Soil hydrological } \\
\text { characteristics }\end{array}$ & $\begin{array}{l}\text { Check which values are measured and those which are not. For a given soil type, determine if the highly } \\
\text { sensitive soil parameters have been measured (for example, the saturated hydraulic conductivity for a clay). }\end{array}$ \\
\hline Plant parameters & \begin{tabular}{l} 
Check suitability of species chosen, plant management regime, and individual parameter values. \\
\hline
\end{tabular}
\end{tabular}


Table 3. Key model outputs checked by Department of Environment and Resource Management for appraisal of an effluent irrigation scheme proposal.

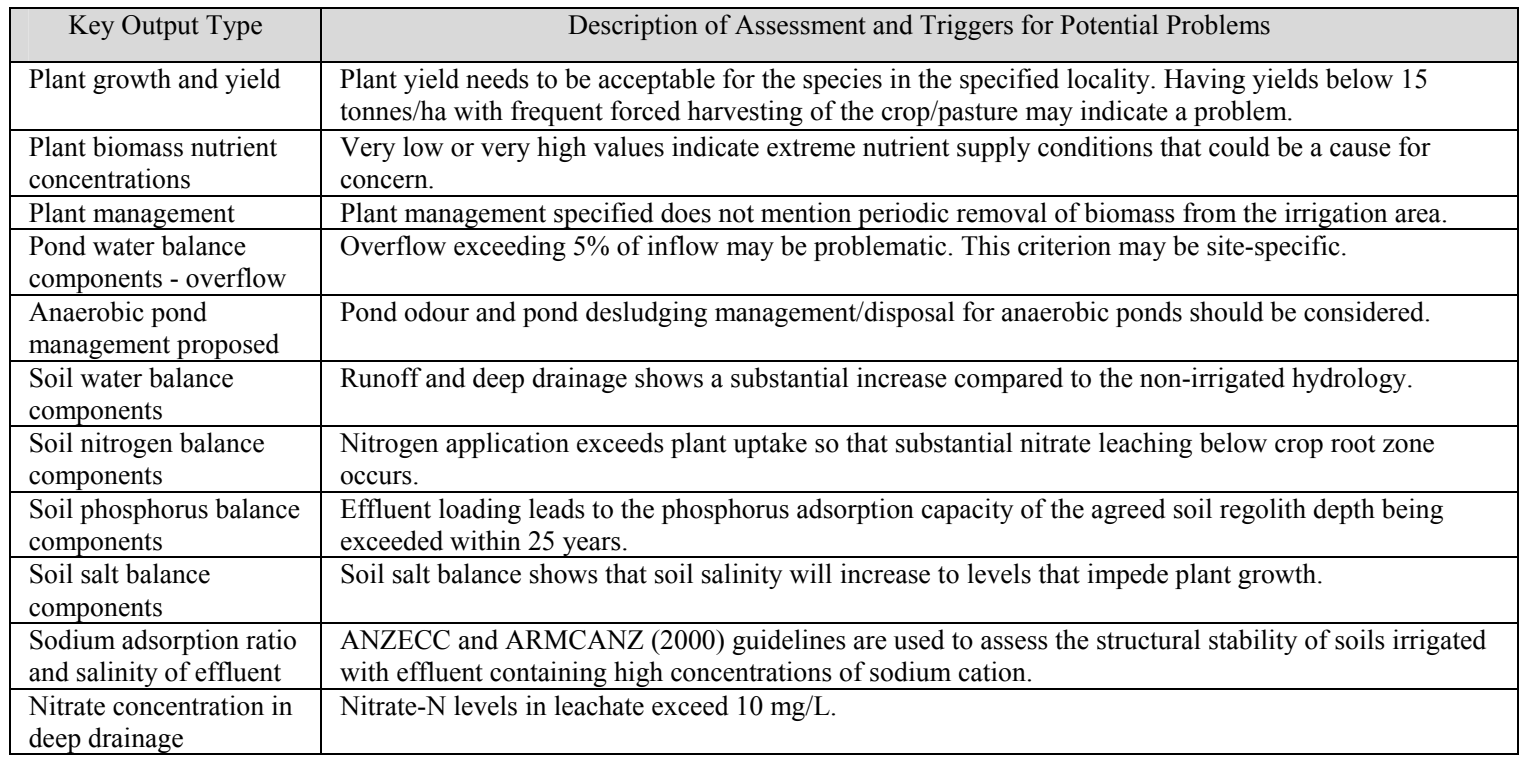

\section{IMPROVED ASSESSMENT OF EFFLUENT IRRIGATION SCHEMES}

\subsection{Developing improved performance criteria}

Performance criteria should encompass important aspects for protecting the environment from harm and give reasonable protection to those parts of the environment most likely to be affected. Since Queensland has some of the highest rainfall areas of Australia, performance criteria for appraising effluent irrigation schemes need to make allowance for this fact.

To formulate criteria, we used the approach of making a detailed list of the possible routes of transfer of water and nutrients from a scheme to its surroundings (the "scheme's environment"), and then consider what form of criterion - if any - might be most appropriate for the discharges via each of these routes. For an effluent irrigation scheme, the criteria must ensure that the application rate of any component of effluent, whether it be water, salts, nitrogen or phosphorus, should not exceed 1) the rate at which it is taken up by the plants and removed from the site, 2) the safe storage of the component in the soil and 3) allowable losses into the environment as per Queensland Water Recycling Guidelines (EPA 2005). It must also be practicable for scheme designers and operators to meet the criteria, and for regulators to use them in formulating approval conditions.

The criteria formulated were tested via MEDLI modelling using a diverse range of climates and soil types (with different permeabilities and phosphorus sorption capacities) with systematic changes in irrigation area and pond storage volume. The model's predictions were then used to indicate whether a scheme having physically practicable ranges of storage capacity (ML) and land area (ha) might be expected to meet the criteria formulated. An example of modelling results used to derive a criterion for the uptake of nitrogen by plants irrigated with treated municipal sewage is shown in Table 4. All the scenarios listed would meet a criterion of $95 \%$ nitrogen uptake, and so a criterion that "at least $95 \%$ of the total nitrogen applied to land needs to be removed as harvested plant biomass on average" was suggested.
Table 4. Average uptake of nitrogen predicted for scenarios across various agro-climatic zones. Each scenario included irrigating the land with treated municipal sewage at the maximum rates used in modelling.

\begin{tabular}{|c|c|c|c|}
\hline Location & $\begin{array}{c}\text { N applied } \\
(\mathrm{kg} / \mathrm{ha} / \mathrm{yr})\end{array}$ & $\begin{array}{c}\mathrm{N} \text { uptake } \\
(\mathrm{kg} / \mathrm{ha} / \mathrm{yr})\end{array}$ & $\begin{array}{c}\% \\
\text { Uptake }\end{array}$ \\
\hline Innisfail & 8.0 & 14.7 & $183^{*}$ \\
\hline Nambour & 14.6 & 20.8 & $142^{*}$ \\
\hline Stanthorpe & 45.1 & 50.9 & $113^{*}$ \\
\hline Cairns & 58.8 & 64.7 & $110^{*}$ \\
\hline Kingaroy & 74.2 & 80.2 & $108^{*}$ \\
\hline Gatton & 95.3 & 101.4 & $106^{*}$ \\
\hline Rockhampton & 121.2 & 126.7 & $105^{*}$ \\
\hline Townsville & 135.2 & 140.8 & $104^{*}$ \\
\hline Blackall & 177.9 & 173.6 & 98 \\
\hline
\end{tabular}

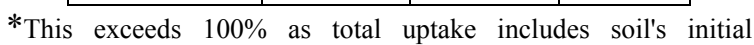
inventory

The results of this exercise resulted in other performance criteria being developed including, 1) relative amounts of wet weather pond overflow (ML/yr) as long-term averages, determined according to climatic 
conditions, 2) nitrogen and phosphorus uptake by plants, 3) effect of salinity on plant yields, and 4) effect of water composition on soil structural stability.

These proposed criteria are still under review by scientists and regulators. Criteria development will also be an ongoing process as monitoring data from existing schemes are collected and become available and data from published field trials in Queensland are analysed.

It should be stressed that, whilst modelling and performance criteria will facilitate the appraisal process, it does not remove the need for assessment by staff with specialist knowledge in managing agricultural systems and assessing environmental outcomes. Of course no one set of criteria can encompass all the irregularities of a biophysical system. Similarly, designers need to understand land management for growing crops because an effluent irrigation scheme is centred on the irrigation area remaining viable for plant growth in the long term. As further key criteria are developed, scheme designs can be adjusted using MEDLI until outputs comply with the criteria. This provides a good example of the potential linkages between modelling and regulatory policy.

\subsection{Improved risk assessment framework}

A further step for improving the assessment of effluent irrigation scheme designs is to develop and apply a broader risk assessment framework, an example of which is shown in Figure 1. One option is to subject all scheme designs to a preliminary risk assessment using pre-set criteria that do not require detailed modelling. Using this framework, schemes of low risk could be approved without need for modelling, whilst those of high risk would need significant redesign to reduce the risk before detailed consideration by DERM. In between these categories are schemes of moderate risk that would need modelling to better quantify their environmental impacts.

Development of the preliminary risk assessment criteria is in progress based on prior assessment experience of schemes designed largely using MEDLI. Examples of categories of criteria under consideration include:

- Distance to sensitive areas including ground water: the smaller the distance, the greater the risk,

- Loading rates compared to lowrisk loading rates: the more the calculated loading rate exceeds the low-risk loading rate, the greater the risk,

- Effluent quality: the poorer the quality (eg salinity), the greater the risk,

- Land suitability for cropping: the poorer the land suitability for irrigation, the greater the risk, and

- Topography: the greater the land slope, the greater the risk.

Where assessment of schemes return high risk for a particular criteria, action could be taken to address that area of concern. Examples of redesigning 'high risk' schemes to lower their risk include: land area increased to reduce deep drainage to groundwater used for supplying drinking water; and relocating a new industry such

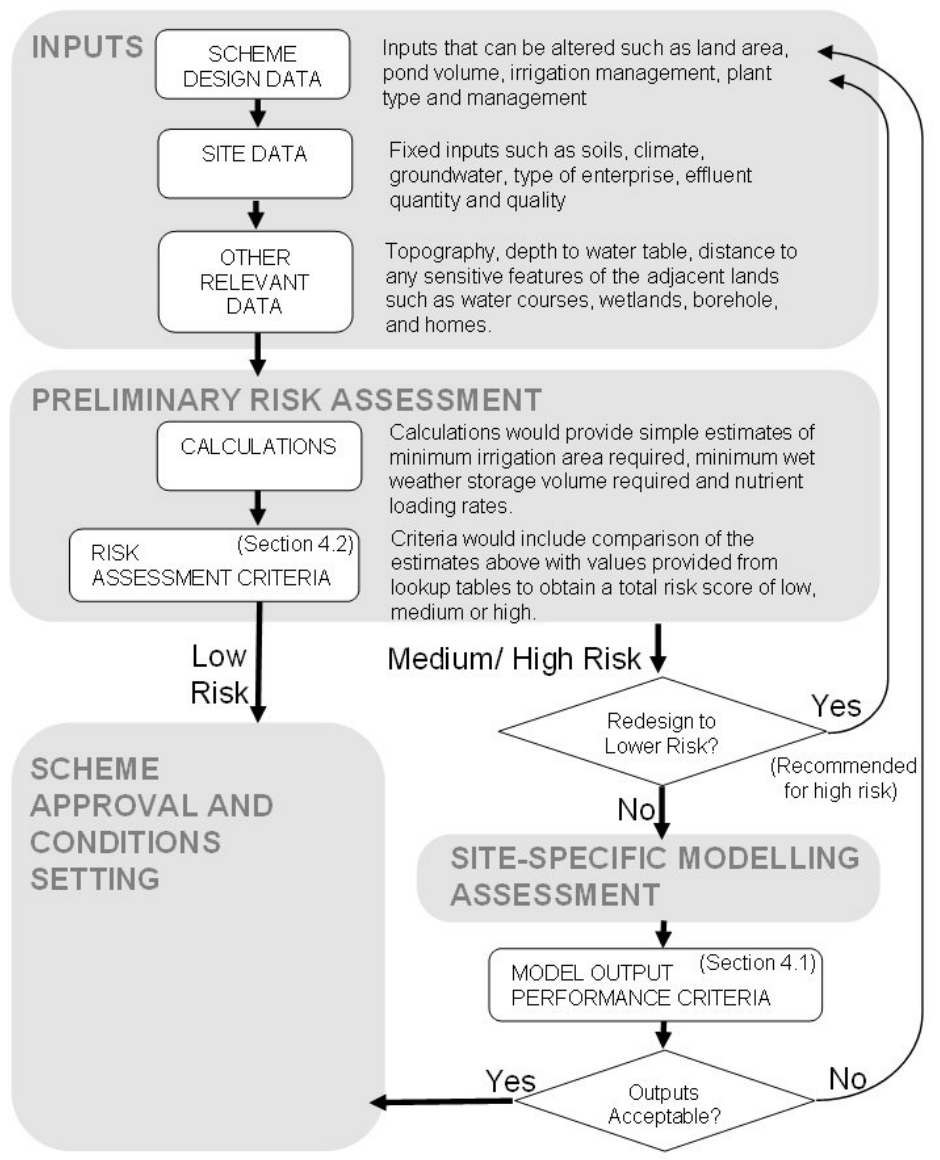

Figure 1. Proposed risk assessment process for effluent irrigation scheme proposals highlighting the preliminary risk assessment step and use of risk assessment criteria. 
such as a tannery to another site where long-term accession of salts to inland surface water and groundwater is no longer an issue.

\section{CONCLUSIONS}

MEDLI has played a very useful role over the past decade in assisting both the designers of effluent disposal systems and those assessing and approving these schemes by providing transparent and well documented outputs that allow potential environmental consequences to be assessed. Key success factors include the clear benefits to a target user audience, the scientific integrity of the model (in terms of algorithms and peer review process), low purchase cost and high user support. This success occurred despite some significant hurdles including a high initial effort to gain competency in its use, lack of software upgrades, lack of advertising, and a small market.

An acceptable MEDLI result involves two levels of consideration. The first relates to the integrity or uncertainty of the model results (considering inputs, parameters and model integrity). The second relates to whether the result is acceptable in terms of environmental impacts at both an on-site and off-site scale. The model has been used to help clearly define criteria that should be used for assessing land disposal schemes in Queensland. These criteria should focus on protecting the environment (i.e. allow for only acceptable losses to the environment), ensure sustainable use of the land (i.e. minimise accumulation and long term affects), are commercially practical, and can readily be used for regulatory assessment, especially for schemes designed using MEDLI. A risk assessment framework is also proposed to help enhance the appraisal process in the future. Low-risk criteria are proposed based on MEDLI modeling experience, and will be used to remove the need for detailed modelling assessment in some cases. Medium and high risk schemes require full assessment, whilst for high risk schemes, significant redesign is recommended.

MEDLI is expected to continue to play an important role in designing and assessment of effluent irrigation schemes, particularly in Queensland. An upgraded version is planned for 2012 and this should overcome a number of the key weaknesses of the current version.

\section{REFERENCES}

ANZECC and ARMCANZ (2000). The Australian and New Zealand Guidelines for Fresh and Marine Water Quality. National Water Quality Management Strategy Paper No 4, Australian and New Zealand Environment and Conservation Council and Agriculture and Resource Management Council of Australia and New Zealand, Canberra. http://www.ea.gov.au/water/quality/nwqms/index.html. Accessed September 2011.

Davis, R. \& Gardner, E. (1996). MEDLI - Bringing effluent irrigation design into the 21st Century. Water, May, June 1996.

DEC (2004). Department of Environment and Conservation (NSW), Environmental Guidelines: Use of Effluent by Irrigation, October 2004.

EPA (2005). Queensland Water Recycling Guidelines, QLD Environmental Protection Agency, Brisbane

Gardner, T., Atzeni, M., McGahan, E., Vieritz, A., and Casey, K. (1996). MEDLI - A computer model to help resolve environmental conflict in intensive rural industries. In: Proceedings of the Resolving Environmental Conflict Conference. 17pp. November. Brisbane, QLD. Institution of Engineers Australia.

Hook, R.A. (1997). MEDLI Model for Effluent Disposal using Land Irrigation. In "Directory of Australian Modelling Groups and Models". CSIRO Australia. pp. 262-267.

Richard, G. A., Pereira, L.S., Raes, D., and Smith, M. (1990). Crop Evapotranspiration (Guidelines for computing crop water requirements), FAO Irrigation \& Drainage Paper No. 56, FAO, Rome. 300p.

Schofield N. (2005). Land Water Australia's Portfolio's Return on Investment 2005. Attachment 11. Effluent Guidelines. http://lwa.gov.au/products/er051011. Accessed August 2011.

Vieritz, A.M., Gardner, T., Littleboy, M., Atzeni, M.G., Beecham, R.E., Casey, K.D., Farley, T., Davis, J.R., Sharma, P.K., McGahan, E.J., Dillon, P.J. (1998). MEDLI - A model for designing sustainable irrigation systems for the reuse of effluent. Environmental Benefits of Soil Management, Conference Proceedings. National Soil Science Conference, Brisbane, 27-29 April 1998. pp 154-161. 